\title{
ON THE PECULIARITY OF THE CARBOHYDRATE METABOLISM OF THE ISOLATED BULLFROG'S HEART
}

\author{
KOROKU HASHIMOTO, YOSHIKO MORITA \\ AND SYUNSUKE MATSUYAMA* \\ Department of Pharmacology, Faculty of Medicine, University of Tokyo, Tokyo, \\ and \\ Iatrochemical Institute, Pharmacological Research Foundation, Tokyo
}

Many authors, especially Weizsächer, Eismyer and Quincke, A. J. Clark and his collaborators performed elaborate works on the metabolism of the isolated frog's heart in various conditions, i.e., oxygen pressure, rate of work, temperature and composition of the perfusion fluid, and the effects of drugs on it, of which informations were collected and critically analysed by A. J. Clark in his monograph "The Metabolism of the Frog's Heart" (1). As he noticed, there is the outstanding advantage of the cold-blooded heart as a subject for metabolic research, because, in spite of the simple structure of the frog's heart, there are many similarities in the cardiac function with that of a warm-blooded heart, as far as it is tested on heart rate, filling degree of the ventricle, temperature, uptake of metabolites and so on. The authors obtained almost the same results using a rather voluminous bullfrog's heart and properly deviced technic, and further analysed more precisely the relation between cardiac work (output, aortic pressure and streaming velocity) and oxygen consumption in the previous papers (Hashimoto et al. (2-3)). However in recent years diverse effects of drugs were observed on the frog's heart by some workers (S. Ellis (4), Hashimoto and Nukada (5)), especially by the use of metabolic inhibitiors. These observations might suggest a certain peculiar feature of the metabolic process of the cold-blooded heart and this peculiarity may admit some diverse reaction of a drug on cardiac function. A further question is; whether this peculiarity could concern the well known facts of the seasonal variation? The authors reported on the seasonal variations of the oxygen uptake of the isolated bullfrog's heart in almost the same experimental conditions, using heparinized blood of the animal itself as perfusion fluid. However glucose and lactic acid concentration in the blood were significantly lower in winter, therefore there are some uncertainties as to the seasonal variations of metabolism of frog's heart without resorting to ascertain the metabolic sources of equal blood levels. Experiments in this paper were undertaken to elucidate the peculiar manner of carbohydrate metabolism of the cold-blooded heart and its relation to the seasonal variation by adding glucose and sodium lactate.

Received for publication January 31, 1958.

* 橋本虎六, 森田淑子, 松山俊介 
PROCEDURES

The method for measuring oxygen consumption, $\mathrm{CO}_{2}$ production, cardiac output and aortic pressure are the same as described in the previous report (2-3). Isolated hearts were driven by electric stimulator in the rate at 20 beats per minute in the constant temperature of $20^{\circ} \pm 0.1^{\circ} \mathrm{C}$., circulating 2 cc. blood of the animal itself which is prevented from coagulation by use of heparin. Glucose, sodium lactate (dl.) or both was initially added into the perfused blood. Blood samples taken at the beginning and exactly after 2 hours perfusion experiment were analysed for glucose by Somogyi's method, lactic acid and pyruvic acid by Barker and Summerson's method. From these determinations, glucose- and lactate-uptake were calculated.

\section{RESULTS}

\section{1) Seasonal variation of metabolism of isolated bullfrog's heart}

The actual data are summerized in table 1. Even though the glucose- and lactate-level in the blood were varied in a rather wider range in each season, oxygen consumption, $\mathrm{CO}_{2}$ production, cardiac work and efficiency were higher in summer than in winter, while the $R Q$ value was lower during summer. A higher cardiac work of summer frogs was due to a higher cardiac output as well as a higher mean blood pressure, i.e. of $1.642 \mathrm{cc} / \mathrm{g} / \mathrm{hr}$., $23.9 \mathrm{~mm} \mathrm{Hg}$ in the average and $1.446 \mathrm{cc} / \mathrm{g} / \mathrm{hr}$., $18.5 \mathrm{~mm} \mathrm{Hg}$ winter. This result is not far off from our previous reports.

TABLE 1.

Summer Frog (From July to August)

\begin{tabular}{|c|c|c|c|c|c|c|c|c|}
\hline 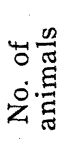 & . & 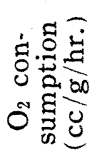 & 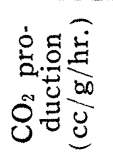 & $\underset{\sim}{\not}$ & 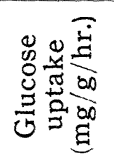 & 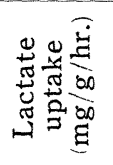 & 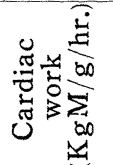 & 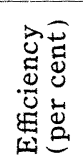 \\
\hline 12 & S.E. & $\begin{array}{c}1.325 \\
\pm 0.056\end{array}$ & $\begin{array}{c}1.175 \\
\pm 0.028\end{array}$ & $\begin{array}{c}0.84 \\
\pm 0.03\end{array}$ & $\begin{array}{c}0.679 \\
\pm 0.098\end{array}$ & $\begin{array}{c}0.679 \\
\pm 0.133\end{array}$ & $\begin{array}{c}0.534 \\
\pm 0.033\end{array}$ & $\begin{array}{c}19.6 \\
\pm 1.06\end{array}$ \\
\hline
\end{tabular}

Winter Frog (From November to February)

\begin{tabular}{c|c|c|c|c|c|c|c|c}
\hline 29 & S.E. & $\begin{array}{c}0.978 \\
\pm 0.036\end{array}$ & $\begin{array}{c}0.884 \\
\pm 0.039\end{array}$ & $\begin{array}{c}0.91 \\
\pm 0.02\end{array}$ & $\begin{array}{c}0.376 \\
\pm 0.020\end{array}$ & $\begin{array}{c}0.660 \\
\pm 0.070\end{array}$ & $\begin{array}{c}0.362 \\
\pm 0.015\end{array}$ & $\begin{array}{c}18.2 \\
\pm 0.81\end{array}$ \\
\hline
\end{tabular}

2) Relation among glucose level, its uptake and oxygen consumption

A fairly well correlation between glucose level and its uptake was found both in summer and in winter as shown in fig. 1 . The bullfrog's heart utilized much more glucose when the glucose level in the circulating blood was higher. This relation was the same as in the warm-blooded heart, however the relation between glucose uptake and oxygen consumption indicated, that the oxygen consumption was depressed by increasing the glucose uptake (fig. 2). 


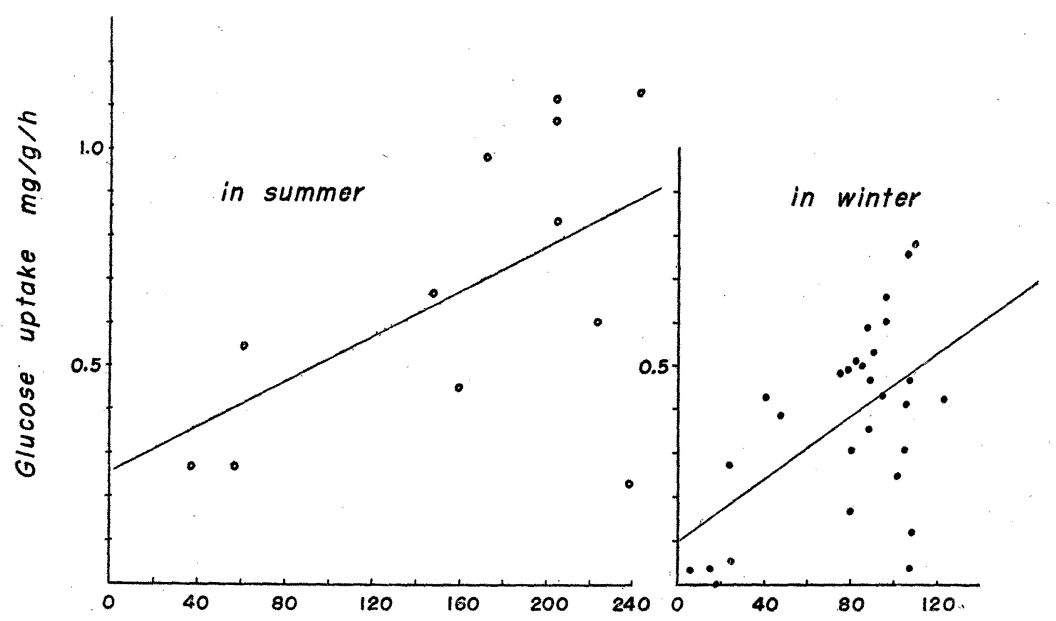

FIG. 1. Glucose concentration in the blood $(\mathrm{mg} / \mathrm{dl}$.).
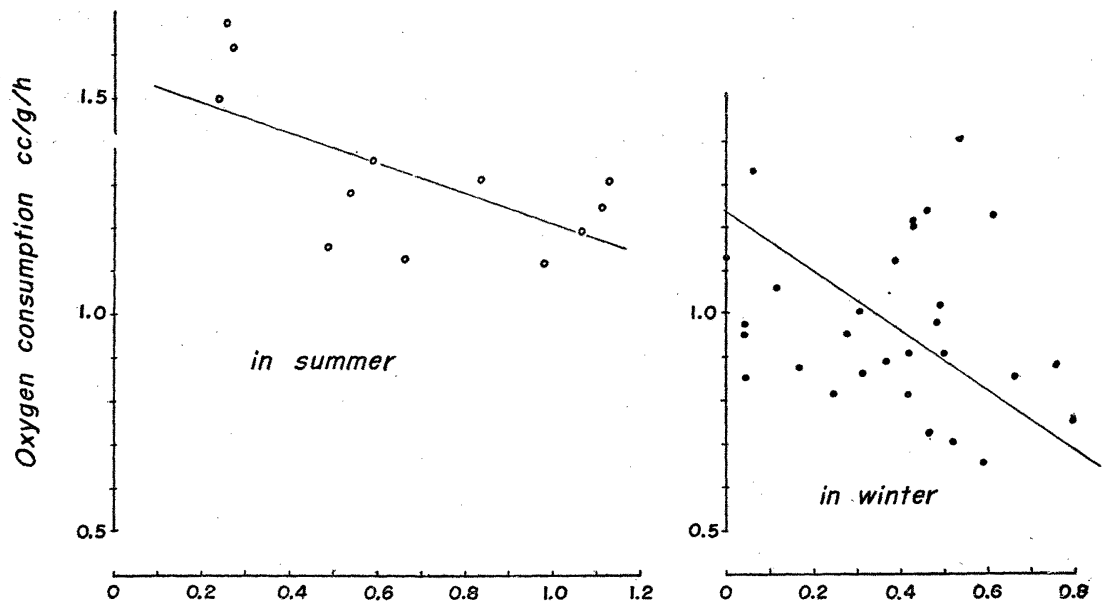

FiG. 2. Glucose uptake ( $\mathrm{mg} / \mathrm{g} / \mathrm{hr}$.).

This phenomenon was quite characteristic of the cold-blooded heart and it was observed either in winter or in summer.

3) Relations among the blood lactate level, its uptake and oxygen consumption

The lactate was much more utilized by the cold-blooded heart in the higher lactate level either in summer or in winter (fig. 3). Furthermore the increased uptake of lactate was accompanied by promotion of the oxygen consumption as observed in the warm-blooded heart (fig. 4). 


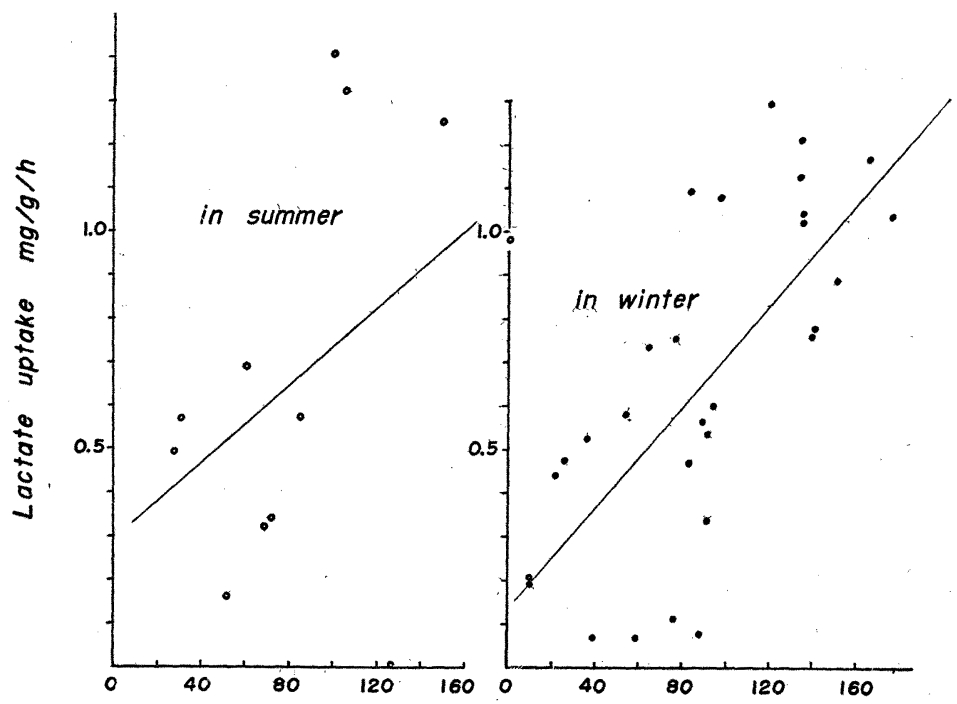

FIG. 3. Lactate concentration in the blood $(\mathrm{mg} / \mathrm{dl}$. $)$.

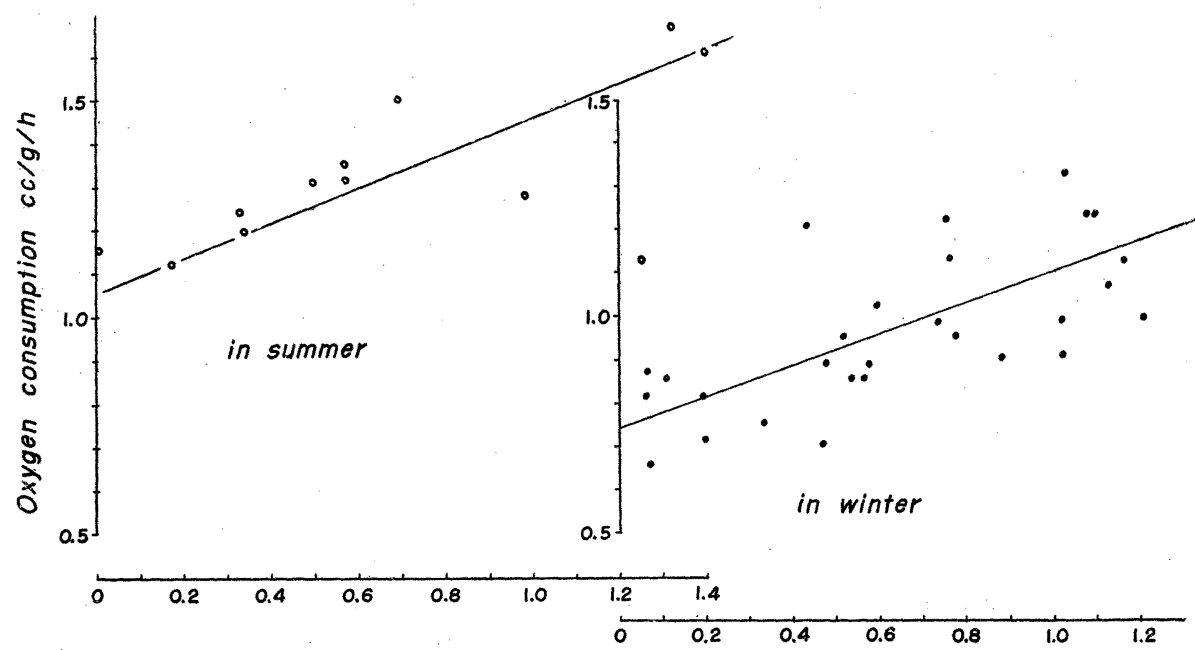

FIG. 4. Lactate uptake ( $\mathrm{mg} / \mathrm{g} / \mathrm{hr}$.).

4) Relation between oxygen consumption and ratio of the lactate uptake to the total carbohydrate uptake (lactate- and glucose-uptake)

The high oxygen consumption was observed when lactate uptake prevailed both in summer and in winter (fig. 5). These results were principally deduced from the contradictory effect of glucose-uptake against that of lactate-uptake on the oxygen consumption as shown in fig. 2 and 4 . 


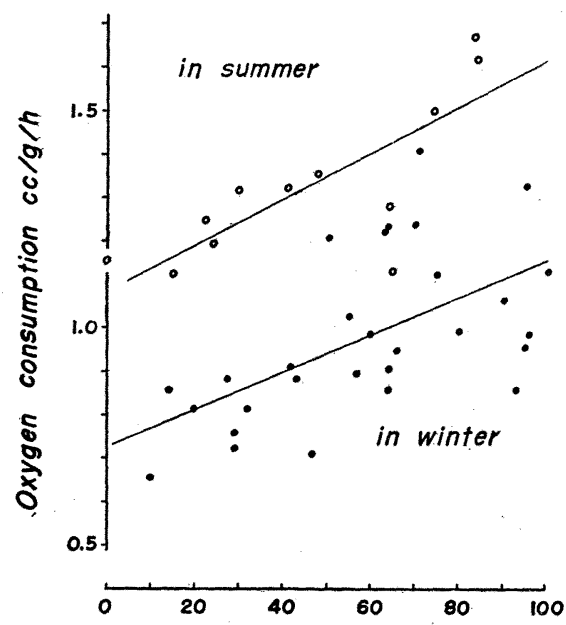

FIG. 5. $\frac{\text { Lactate uptake } \times 100}{\text { Gulcose and lactate uptake }}(\%)$

\section{5) On cardiac work}

The cardiac work was not related to the amount of the glucose uptake, the lactate uptake, nor the $R Q$ value.

\section{DISUSSION}

On the metabolic studies of the isolated frog's heart, A. J. Clark and his collaborators investigated the effect of the alteration of composition of perfusion fluid on the carbohydrate metabolism and oxygen consumption. Among their data, it is worthy of note that the glucose uptake was remarkably enhanced when the frog's heart was perfused with frog's blood, while there was no appreciable glucose uptake, when a mixture of Ringer-serum (10 per cent) -glucose ( 0.1 per cent) solution or Ringer-glucose solution was used. This observation was rather difficult to be explained, but he correctly noticed that by the use of frog's blood as perfusion fluid, the sugar appeared to be oxidized ((1): p. 114)). In addition, by using frog's blood, the oxygen consumption of the frog's heart was almost 30 per cent greater than with Ringer's solution or Ringer-serum mixture. The lactate was taken up by the heart regardless of the composition of perfusion fluid in contrast with the glucose uptake. Therefore we can say that the choice of blood as perfusion fluid is the most adequate procedure to get an undistorted information on the metabolic state of the frog's heart. In these experiments, the authors used the blood of the animal itself and demonstrated the definite evidence of the peculiar manner of the carbohydrate metabolism of the cold-blooded heart of a bullfrog.

One point which we have to consider, is the magnitude of the metabolism of red cells contained in the perfused blood. The amount of the oxygen consumption of $2 \mathrm{cc}$. blood was up to around 10 per cent of that of the isolated heart perfused with the blood. Therefore we reasonably expect that each determination may be slightly overestimated. However it should not affect a general information on the metabolism of the isolated heart. 
The lactate level in the arterial blood is usually quite high and almost the same or sometimes leaning much more to the glucose level as reported previously $(52.2 \mathrm{mg} / \mathrm{dl}$. of lactic acid and $40.5 \mathrm{mg} / \mathrm{dl}$. of glucose in average were determined in summer, 23.0 and $18.0 \mathrm{mg} / \mathrm{dl}$. respectively in winter). It is for this reason that we added sodium lactate, glucose or both for doing away with the seasonal variation of blood constitutents.

In this study, dl. lactate was used. In preliminary experiments, it was observed that an added $d l$-lactate was completely consumed at the end of perfusion. That is to say that $d$-lactate is certainly utilized, even though there may be some difference on utility between $d$ - and $l$-lactate.

With regards to the uptake of a metabolic source, there are similar relations between concentration in the blood and uptake by the heart for either glucose or lactate, such as those observed in the warm-blooded heart. However the sequence of the enhanced glucose uptake and reduced oxygen consumption is the distinctive feature of the cold-blooded heart which differs decisively from that of the warm-blooded heart (Goodale and Hackel (6), Bing et al (7)), because in the warm-blooded heart, the enhanced uptake of glucose as well as lactate accompanies the increase of oxygen consumption. This peculiar feature persisted in all seasons, even though the seasonal variations were observed. From the analysis of data it can be concluded that the oxygen consumption of the bullfrog's heart is steered by the balance between glucose- and lactateuptake either in summer or in winter.

Why are glucose and lactate consumed in the alternative way in the frog's heart, while in the warm-blooded animal the heart consumes lactate much more easily? The Pasteur effect might act effectively on taking up glucose and lactate. In other words, the speed of the oxidative process might be curbed by the glycolysis. Then the prevailing glucose uptake at the higher glucose level may result in the reduction of the lactate uptake. In the case of a higher lactate level, the promoted lactate uptake may stimulate the oxidative process, therefore it depresses the glucose uptake. Here, it is proper to cite the high glycolytic power of the cardiac tissue of the frog (4.0 of $\mathrm{QO}_{2}$ and 7.0 of $Q_{\mathrm{N}_{2}}^{\mathrm{N}_{2}}$ by Barron et al. (8)) and also the high sensitiveness to the Pasteur effect which was observed by the use of an oxidative inhibitor, (Hashimoto (5)) while in the warm-blooded animal the lactate level is usually far lower and the cardiac tissue is one of the tissues which undergoes a potent oxidative process (11.1 of $Q_{\mathrm{O}_{2}}$ and 4.2 of $Q_{\mathrm{C}_{2}}^{\mathrm{N}_{2}}$ as measured in a rat's cardiac slice by Barron et al.).

In conclusion, this peculiar manner of carbohydrate metabolism of the coldblooded heart is probably due to almost the same glucose and lactate level in the arterial blood in the ordinary animals and the same activity of the glycolytic and oxidative process in the cardiac tissues.

The authors believe that it is worthy to make a note on the seasonal variations of the cardiac efficiency. It was calculated the higher value in summer, however another energy source, for instance fat, is expected to be utilized much more in summer as the low RQ value indicated. Furthermore the remarkable seasonal variation of glycogen content in the cardiac tissue, i.e. 2.36 
per cent in the average, standard error \pm 0.43 in winter and 0.67 per cent, \pm 0.04 in summer was previously reported by us. As the glycogen content might indicate the degree of the activity of glycolytic process, the non-oxidative process would hold a rather greater part of the energy production for the cardiac activity during winter. Therefore so called efficiency is expected to be over-estimated in this season. Therefore one should be careful to express the degree of the cardiac function in terms of efficiency in the cold-blooded heart.

Clark and his collaborator's data showed a low RQ value when the lactate was added to the perfused Ringer solution ((1): p. 118)). In our condition we could not observe such relation. Furthermore, we could not find any relation between the cardiac work and the glucose- or the lactate uptake. Therefore it seems no difference, whether glucose or lactate is used for the nutrition in the perfusion experiment as far as the blood is perfused.

\section{SUMMARY}

Using isolated bullfrog's hearts which were perfused with heparinized blood of animal itself, a distinctive feature was observed on carbohydrate metabolism of the cold-blooded heart. When glucose was predominantly taken up by the heart, its oxygen consumption was depressed, while preferential uptake of lactate enhanced oxygen consumption. In consequence the extent of oxygen consumption was controlled by the balance of glucose- and lactate uptake when the heart rate, temperature, aortic resistance and blood volume were kept constant as possible. This characteristic manner of carbohydrate metabolism was not affected by the seasonal variation. It is probably due to the potent glycolytic power of the cardiac tissue of the bullfrog.

This work was supported in part by a grant from the Ministry of Education.

\section{REFERENCES}

1. CLARK, A. J. The metabolism of the frog heart, London: Oliver and Boyd, 1938.

2. Hashimoto, K. And Nukada, H. Jap. J. Physiol. 1: 331, 1951.

3. HAShimoto, K., NUKADA, H. ANd Morita, Y. Folia Pharmacol. Jap. 50: 137, 1954.

4. Hashimoto, K., Shigei, T., Morita, Y. And Matsuyama, S. Folia Pharmacol. Jap. 52: 559, 1956.

5. Ellis, S. J. Pharmacol. Exp. Therap. 109: 231, 1953.

6. Hashimoto, K. AND NuKada, H. Folia Pharmacol. Jap. 50: 76, 1954.

7. GoOdAle, W. T. AND HACKEL, D. B. Circulation Research 1: 509, 1953.

8. BING, R. et al. Am. J. Med. 15: 284, 1953.

9. Guzmann Barron, E. S., Sights, W. P. And Wilder, V. Arch. exp. Path. u. Pharmakol. 219: 338, 1953. 